\title{
Novel ghrelin mimetic is safe and effective as a GH stimulation test
}

A single oral dose of the ghrelin mimetic macimorelin is safe, well-tolerated and effective for the diagnosis of growth hormone $(\mathrm{GH})$ deficiency in adults, say US researchers.

The diagnosis of adult GH deficiency is often challenging. For a definitive diagnosis to be made, most patients require a $\mathrm{GH}$ stimulation test, which currently involves administration of parenteral substances, requires trained personnel and monitored facilities, and can be associated with potentially hazardous effects, such as hypoglycaemia.

"We hypothesized that macimorelin, a novel ghrelin mimetic with good oral bioavailability and rapid absorption, would induce an increase in circulating GH levels in healthy individuals but not in patients with GH deficiency," recounts senior investigator George R. Merriam.

The researchers determined peak $\mathrm{GH}$ levels in 50 patients with adult $\mathrm{GH}$ deficiency and 48 control individuals following macimorelin administration and found that the sensitivity and specificity of the ghrelin receptor agonist for the diagnosis of adult $\mathrm{GH}$ deficiency was similar to that of previously established GH stimulation tests. No clinically apparent adverse effects occurred.

"This novel oral test agent could become the basis for a safe, simple, rapid and convenient method to diagnose adult GH deficiency, especially for patients in whom other provocative tests are contraindicated," conclude the authors.

Linda Koch

Original article Garcia, J. M. et al. Macimorelin (AEZS130)-stimulated growth hormone (GH) test: validation of a novel oral stimulation test for the diagnosis of adult GH deficiency. J. Clin. Endocrinol. Metab. doi:10.1210/ jc. 2013-1157 